\title{
A high-amylopectin diet caused hepatic steatosis associated with more lipogenic enzymes and increased serum insulin concentration
}

\author{
Jun $\mathrm{He}^{1,2 *}$, Daiwen Chen ${ }^{1,2}$, Keying Zhang ${ }^{1,2}$ and Bing Yu ${ }^{1,2}$ \\ ${ }^{1}$ Institute of Animal Nutrition, Sichuan Agricultural University, Yaan, Sichuan 625014, People's Republic of China \\ ${ }^{2}$ Key Laborotary of Animal Disease-Resistance Nutrition, Ministry of Education, People's Republic of China
}

(Received 20 September 2010 - Revised 21 January 2011 - Accepted 15 March 2011 - First published online 1 June 2011)

\section{Abstract}

Starch is the major energy source for monogastric mammals and humans. The present study was conducted to evaluate the liver metabolic responses of weaned pigs fed with different dietary starches. A total of sixteen weaned pigs were fed with two experimental diets containing either cassava starch (CS, 80\% amylopectin and 20\% amylose) or maize starch (70\% amylopectin and 30\% amylose). The present results showed that the growth performance was not affected by different dietary starches $(P>0 \cdot 05)$. However, ingestion of CS not only increased the lipid content in liver tissues, but also elevated the concentrations of serum cholesterol and insulin $(P<0.05)$. The metabolic responses induced by CS were associated with more lipogenic enzymes such as fatty acid synthase and 3-hydroxy-3-methyl-glutaryl-CoA reductase in liver $(P<0.05)$. Real-time PCR quantification for lipid metabolic genes indicated that ingestion of CS not only up-regulated the expression of these lipogenic genes, but also decreased the expression of lipolytic genes. These results suggested that the metabolic responses of weaned pigs fed with different dietary starches may vary widely depending on their composition, and ingestion of starches that are high in amylopectin may produce a stronger insulinaemic response and lead to an up-regulation of lipogenesis in the liver.

\section{Key words: Starch nutrition: Energy metabolism: Lipid: Liver: Weaned pigs}

Dysfunctional energy metabolism underlies the development of obesity and obesity-related complications such as hepatic steatosis, diabetes and heart disease ${ }^{(1)}$. It is a well-known fact that carbohydrate is the most prevalent source of energy for monogastric mammals and humans. Carbohydrates not only provide the substrate for the Krebs cycle, but also act as a regulator for lipid metabolism ${ }^{(2,3)}$. Upon consumption of excess carbohydrate, digestion yields simple sugars that are converted to pyruvate (glycolysis), which is either oxidised to provide energy or channelled into pathways for synthesis of fatty acids (lipogenesis) when energy is available ${ }^{(3)}$. The coordinated regulation of these metabolic processes allows the efficient utilisation of dietary carbohydrates, and key enzymes involved in carbohydrate metabolism are tightly regulated by hormones and dietary nutrients ${ }^{(4)}$.

Previous studies have indicated that in monogastric mammals the metabolic responses induced by different dietary carbohydrates are widely variable ${ }^{(5,6)}$. In humans, isoenergetic replacement of dietary starch with sucrose, in the short term, resulted in elevated plasma TAG and cholesterol concentrations $^{(6,7)}$ and impaired glucose tolerance ${ }^{(8)}$. Similar adverse effects of high sucrose consumption have been reported for non-human primates and a number of laboratory animals ${ }^{(2,9)}$. Starch, acting as the main energy source of the daily diet, is the most prevalent carbohydrate consumed by monogastric mammals. However, the metabolic responses induced by different dietary starches may vary widely depending upon their sources and polymer structures ${ }^{(10,11)}$. For instance, starches that are high in amylopectin are easily digested, which may lead to a rapid increase in blood glucose and insulin concentration, whereas starches with more amylose may result in moderate glycaemic and insulinaemic responses ${ }^{(12-14)}$. Although these metabolic responses were previously studied in both humans and other monogastric mammals, still less is known about the mechanisms behind these responses. More importantly, few studies have investigated the relationship between hepatic lipid metabolism and starch composition. Therefore, the aim of the present study was to evaluate the metabolic responses of weaned pigs fed with different dietary starches, and mechanisms behind these responses were investigated on a molecular basis.

Abbreviations: CS, cassava starch; GH, growth hormone; MS, maize starch.

*Corresponding author: J. He, fax +86 835 2885164, email hejun8067@163.com 


\section{Materials and methods}

\section{Starches}

Purified cassava starch (CS, 80\% amylopectin and 20\% amylose) and maize starch (MS, 70\% amylopectin and 30\% amylose) were purchased from Chengdu food market (Chengdu, Sichuan, China).

\section{Animals and diets}

The experimental protocols used in the present study were approved by Sichuan Agricultural University Institutional Animal Care and Use Committee. Sixteen weaned pigs (Duroc $\times$ Landrace $\times$ Yorkshire) with an average initial body weight of 7.37 (SEM 0.25 ) kg were selected and randomly allotted to two dietary treatments with equal numbers of males and females in each group. The experimental diet was formulated on the basis of nutrient requirements established by the National Research Council (1998) for 5-10 kg pigs $^{(15)}$. Either CS or MS was used as the sole dietary energy source. There were no discrepancies for other nutrient components. Dietary amino acids were supplied by dehulled soyabean meal, extruded soyabean and fishmeal, and vitamin and minerals were supplied by vitamin and mineral supplements (Table 1). Synthetic DL-methionine was added to the diets to meet minimal methionine-cystine requirements.

\section{Animal housing and tissue sampling}

The pigs were housed individually in metabolism cages $(0.7 \times 1.5 \mathrm{~m})$ with woven wire flooring in an environmentally controlled room $\left(22-24^{\circ} \mathrm{C}\right)$ and were given ad libitum access to water through a water nipple. They were hand-fed four times/d (08.00, 12.00, 16.00 and 20.00 hours) in bowl feeders to make sure fresh feed was available, and were allowed a $7 \mathrm{~d}$ adjustment to the experimental diets. The diet adjustment period was followed by a $21 \mathrm{~d}$ experimental period. Weights and feed consumption of the pigs were determined daily throughout the trial. The blood samples were collected by venepuncture at 07.00 hours on day 14 . At the end of the trial, pigs were euthanised with an intravenous injection of pentobarbital sodium $(50 \mathrm{mg} / \mathrm{kg}$ body weight $)$ and the liver samples were collected, weighted and stored at $-80^{\circ} \mathrm{C}$.

\section{Biochemical analysis}

The liver and serum lipids were extracted and purified ${ }^{(16)}$. TAG and cholesterol levels were measured using the method described by Hercberg et $a l .{ }^{(17)}$. Insulin, growth hormone (GH) and glucagon levels were measured using electrochemiluminescence immunoassays (Roche Diagnostics, Meylan, France). All the assay kits were purchased from Tosoh Corporation (Kyoto, Japan). The activities of liver glucose6-phosphate dehydrogenase, fatty acid synthase, acyl-CoA oxidase and 3-hydroxy-3-methylglutaryl-CoA reductase were assayed according to methods described by Ide et al. ${ }^{(18)}$.
Table 1. Ingredient and chemical composition of experimental diets (as fed-basis)

\begin{tabular}{|c|c|c|}
\hline \multirow[b]{2}{*}{ Ingredients (\% of diet) } & \multicolumn{2}{|c|}{ Chemical composition } \\
\hline & CS & MS \\
\hline CS & 54.50 & \\
\hline MS & & 54.50 \\
\hline Dehulled soyabean meal & 2.00 & 2.00 \\
\hline Extruded soyabean & $10 \cdot 00$ & $10 \cdot 00$ \\
\hline Soya protein concentrate & $17 \cdot 83$ & $17 \cdot 83$ \\
\hline Whey powder & $7 \cdot 30$ & $7 \cdot 30$ \\
\hline Fishmeal & $6 \cdot 00$ & $6 \cdot 00$ \\
\hline $\mathrm{CaHPO}_{4}$ & 0.70 & 0.70 \\
\hline $\mathrm{CaCO}_{3}$ & 0.55 & 0.55 \\
\hline Salt & 0.15 & 0.15 \\
\hline Choline chloride (50\%) & $0 \cdot 10$ & $0 \cdot 10$ \\
\hline L-Lysine & 0.00 & 0.00 \\
\hline Methionine & 0.17 & 0.17 \\
\hline Threonine & 0.01 & 0.01 \\
\hline $\mathrm{Cr}_{2} \mathrm{O}_{3}$ & 0.40 & 0.40 \\
\hline Trace mineral premix* & 0.20 & 0.20 \\
\hline Vitamin premix† & 0.04 & 0.04 \\
\hline Additives & 0.05 & 0.05 \\
\hline Total & $100 \cdot 00$ & $100 \cdot 00$ \\
\hline Dietary energy (MJ/kg) & 14.50 & 14.50 \\
\hline Crude protein (\%) & 19.99 & 19.99 \\
\hline $\mathrm{Ca}(\%)$ & 0.80 & 0.80 \\
\hline Available P (\%) & 0.41 & 0.41 \\
\hline L-Lysine (\%) & 1.29 & 1.29 \\
\hline Methionine + cystiene (\%) & 0.74 & 0.74 \\
\hline Threonine (\%) & 0.81 & 0.81 \\
\hline Tryptophan (\%) & 0.25 & 0.25 \\
\hline Arginine (\%) & 1.49 & 1.49 \\
\hline $\mathrm{Na}(\%)$ & 0.20 & 0.20 \\
\hline Crude fibre (\%) & 1.37 & 1.37 \\
\hline Crude fat (\%) & $2 \cdot 60$ & $2 \cdot 60$ \\
\hline Ash (\%) & $3 \cdot 21$ & $3 \cdot 21$ \\
\hline
\end{tabular}

CS, cassava starch; MS, maize starch.

* Supplied (per kg diet): $\mathrm{Fe}$ as $\mathrm{FeSO}_{4} \cdot 7 \mathrm{H}_{2} \mathrm{O}, 100 \mathrm{mg} ; \mathrm{Mn}$ as $\mathrm{MnSO}_{4} \cdot 7 \mathrm{H}_{2} \mathrm{O}, 40 \mathrm{mg}$; $\mathrm{Zn}$ as $\mathrm{ZnO}, 80 \mathrm{mg}$; $\mathrm{Cu}$ as $\mathrm{CuSO}_{4} \cdot 5 \mathrm{H}_{2} \mathrm{O}, 10 \mathrm{mg}$; Se as $\mathrm{NaSeO}_{3}, 0.3 \mathrm{mg}$ and I as $\mathrm{KI}, 0.3 \mathrm{mg}$.

† Supplied (per kg diet): $5.7 \mathrm{mg}$ vitamin $\mathrm{A}, 36.7 \mathrm{mg}$ vitamin $\mathrm{E}, 0.01 \mathrm{mg}$ vitamin $\mathrm{D}$ $1.1 \mathrm{mg}$ vitamin $\mathrm{K}$ (menadione dimethylpyrimidinoe bisulfate), $5 \mathrm{mg}$ vitamin $B_{1}$, $15 \mathrm{mg}$ riboflavin, $25 \mathrm{mg}$ niacin, $30 \mathrm{mg}$ D-pantothenic acid and $0.05 \mathrm{mg}$ vitamin $B_{12}$.

\section{RNA extraction}

Total RNA was isolated from liver using TRIzol (Invitrogen, Carlsbad, CA, USA) and further purified by RNeasy Mini Kit (Qiagen, Valencia, CA, USA). All the procedures were carried out as per the manufacturer's protocol. The concentration of RNA was determined using spectrophotometry based on absorbance at $260 \mathrm{~nm}$ and integrity was monitored using an Agilent 2100 Bioanalyzer (Agilent Technologies, Santa Clara, CA, USA).

\section{Real-time RT-PCR}

Real-time PCR primers were designed (Takara, Dalian, Liaoning, China) to assay six genes related to lipid metabolism (Table 2). $\beta$-Actin was used as the reference gene. Briefly, 500 ng RNA was reverse transcribed using high-capacity cDNA Reverse Transcription Kit (PN 4368814; Invitrogen) for each pig. Real-time RT-PCR for six target genes and the housekeeping gene were performed using Applied Biosystems (Foster City, CA, USA) Power SYBR Green PCR Master Mix 
Table 2. Primer sequences of genes selected for analysis by real-time RT-PCR

\begin{tabular}{llll}
\hline Gene & Accession no. & Forward primer & Reverse primer \\
\hline hmgr & NM_001122988 & GAGTGGTCCCACAAATGAAG & CACGGTCCCGATCTCTATG \\
acox1 & AK232470 & TGACGGGAATGTTATGAAA & CAGGTGCTTGTGGTAAGA \\
fasn & NM_001099930 & GTGTGAGCAGTTCTGATG & AGCCTATCATGCTGTAGC \\
cpt1a & NM_001129805 & ACAAGCCATAGTCTTAACGAAA & GCCAGTCCAGGATAACAAA \\
ppar $\alpha$ & AK232864 & CGTATCCTGCGTATGAAG & GTGTGAGCCTAAGAATT \\
$d g a t$ & NM_214051 & ACCTACCGCGATCTCTAC & AGCTGGATGAGGACAGCAT \\
$\beta$ - Actin & AY550069 & TCTGGCACCACACCTTCT & TGATCTGGGTCATCTTCTCAC \\
\hline
\end{tabular}

Temp, temperature.

in a Bio-Rad iCycler with minor modifications (Bio-Rad, Hercules, CA, USA). Fluorescein was added at a final concentration of $10 \mathrm{~nm}$ as the reference dye. Cycling conditions were as follows: $95^{\circ} \mathrm{C}$ for $5 \mathrm{~min}$, forty-five cycles of $95^{\circ} \mathrm{C}$ for $30 \mathrm{~s}$, appropriate annealing temperature (Table 2) for $30 \mathrm{~s}$, $72^{\circ} \mathrm{C}$ for $30 \mathrm{~s}$, followed by $72^{\circ} \mathrm{C}$ for $5 \mathrm{~min}, 95^{\circ} \mathrm{C}$ for $1 \mathrm{~min}$, $55^{\circ} \mathrm{C}$ for $1 \mathrm{~min}$, followed by a melt curve analysis of eighty cycles of $10 \mathrm{~s}$ at $55^{\circ} \mathrm{C}$ with a $0.5^{\circ} \mathrm{C}$ increase every cycle.

\section{Statistical analysis}

Gene expression data from replicate samples were averaged and analysed using the Pfaffl $^{(19)}$ method to measure the difference between the cassava and maize cycle threshold values. Growth performance, metabolic enzymes and serum data were analysed by SPSS 13.0 (SPSS, Inc., Chicago, IL, USA). Determination of statistical significance was carried out by independent-sample $t$ test. Data were expressed as means with their standard errors. Differences with $P<0.05$ were considered to be significant.

\section{Results}

\section{Growth performance}

The growth parameters are reported in Table 3. There were no significant differences $(P>0.05)$ in either average daily body weight gain or feed intake between the CS and MS groups

Table 3. Effects of different dietary starches on growth performance, metabolic hormones and hepatic lipid concentrations in weaned pigs (Mean values with their standard errors)

\begin{tabular}{|c|c|c|c|c|}
\hline & \multicolumn{2}{|c|}{ CS } & \multicolumn{2}{|c|}{ MS } \\
\hline & Mean & SEM & Mean & SEM \\
\hline Average daily gain (g/d) & 378.9 & $21 \cdot 3$ & $386 \cdot 7$ & $28 \cdot 2$ \\
\hline Average daily intake $(\mathrm{g} / \mathrm{d})$ & $492 \cdot 7$ & $29 \cdot 1$ & $509 \cdot 4$ & $35 \cdot 6$ \\
\hline $\begin{array}{l}\text { Serum growth hormone } \\
(\mathrm{ng} / \mathrm{ml})\end{array}$ & 1.03 & 0.04 & 0.92 & 0.03 \\
\hline Serum insulin (pmol/l) & $72 \cdot 42^{*}$ & 5.93 & $56 \cdot 24$ & $5 \cdot 17$ \\
\hline Serum glucagon (pg/ml) & $31 \cdot 33$ & $6 \cdot 12$ & $26 \cdot 51$ & $5 \cdot 74$ \\
\hline $\begin{array}{l}\text { Liver total fat }(\mathrm{g} / 100 \mathrm{~g} \\
\text { wet tissue) }\end{array}$ & $8 \cdot 91^{*}$ & 0.62 & $5 \cdot 38$ & 0.33 \\
\hline Liver TAG $(\mu \mathrm{mol} / \mathrm{g})$ & $69.12 \dagger$ & $7 \cdot 11$ & 58.34 & $6 \cdot 32$ \\
\hline Liver cholesterol $(\mu \mathrm{mol} / \mathrm{g})$ & $3 \cdot 42^{* *}$ & 0.25 & $2 \cdot 78$ & 0.19 \\
\hline
\end{tabular}

CS, cassava starch; MS, maize starch.

Mean value was significantly different from that of the MS group: * $P<0.05$, ** $P<0.01$.

† Mean value tended to be significantly different from that of the MS group $(P<0.1)$. during the $21 \mathrm{~d}$ experimental period; weight gains were 378.9 (SEM 21.3) and 386.7 (SEM 28.2) g/d in the CS and MS groups respectively. The daily feed intakes of the CS and MS groups were $492 \cdot 7$ (SEM 29.1) and $509 \cdot 4$ (SEM 35.6) g/d respectively.

\section{Serum metabolites and hormones}

No significant difference in serum glucose concentration was observed between the two groups (Fig. 1). However, ingestion of CS acutely increased the serum cholesterol concentration (2.04 (sem 0.13) v. 1.54 (SEM $0 \cdot 10) \mathrm{mmol} / 1, \quad P<0.05)$. In addition, the serum TAG concentration increased by $14.9 \%$ in the CS group (Fig. 1). There were no significant differences in serum GH and glucagon concentrations between the two groups $(P>0.05)$. In contrast, ingestion of CS significantly elevated the serum insulin concentration (Table 3 ).

\section{Lipid content and metabolic enzymes in liver}

Ingestion of CS significantly elevated the liver total fat and cholesterol concentration $(P<0.05)$. In addition, the TAG concentration increased by $18.5 \%$ in this group (Table 3 ). The activities of several critical enzymes involved in lipid metabolism were measured (Fig. 2). No significant difference was observed for the activity of glucose-6-phosphate dehydrogenase between the two groups $(P>0 \cdot 05)$. However, ingestion of CS significantly elevated the fatty acid synthase and 3-hydroxy-3-methyl-glutaryl-CoA reductase activities in the liver $(P<0 \cdot 05)$. The activity of acyl-CoA oxidase was lower in the CS group than that in the MS group $(P<0.05)$.

\section{Hepatic gene expression}

Quantitative real-time RT-PCR assays were designed for six genes expressed in liver. The genes were selected based on their involvement in lipid metabolism or their importance as components of the metabolic process. The present results indicated that ingestion of CS significantly elevated the transcription of lipogenic genes such as fatty acid synthase and 3-hydroxy-3-methylglutaryl-coenzyme A reductase (Fig. 3). However, the expression of lipolytic genes such as acyl-CoA oxidase 1 (acox1) and ppara decreased 1.18- and 1.24-fold respectively $(P<0.05)$. No significant differences were observed for diacylglycerol acyltransferase and carnitine palmitoyltransferase $1 \mathrm{~A}$ transcription between the two groups $(P>0 \cdot 05)$. 


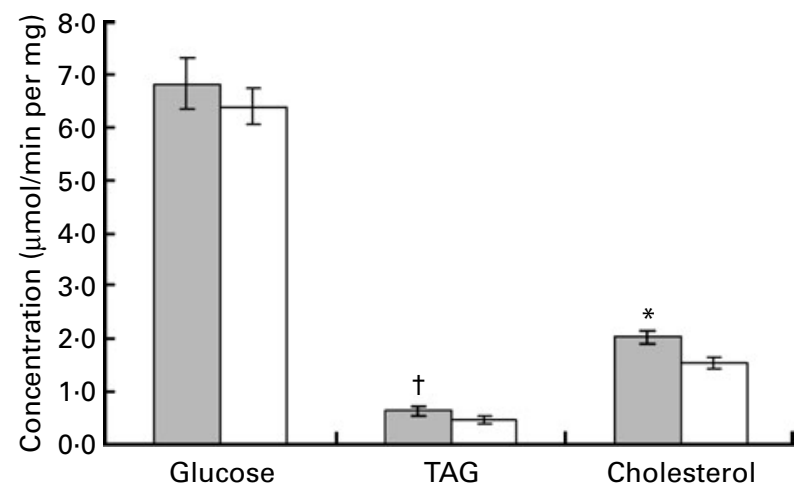

Fig. 1. Effect of different dietary starches on serum glucose and lipid concentrations. Mean values were significantly different: ${ }^{\star} P<0.05, \dagger P<0.10$. $\square$, Cassava starch (CS); $\square$, maize starch (MS).

\section{Discussion}

Starch is the most important energy source for monogastric mammals. However, the digestibilities of starches from different sources are widely variable ${ }^{(10,11,13)}$. Starches with a high amount of amylose are difficult to hydrolyse, whereas fully gelatinised amylopectin is easily digested, which can serve as a source of rapidly digestible starch and cause a stronger glycaemic and insulinaemic responses ${ }^{(10-13)}$. In the present study, the growth performance of weaned pigs was not affected by different dietary starches. However, ingestion of CS significantly elevated the serum cholesterol (32.4\%) and insulin $(28.8 \%)$ concentrations $(P<0.05)$. Previous studies have indicated that ingestion of carbohydrate results in elevated blood glucose, which rapidly triggers insulin release from $\beta$-cells of the endocrine pancreas ${ }^{(11,20)}$. Unexpectedly, no significant difference was observed for serum glucose concentration between the two groups. This should be attributed, in part, to the elevated serum insulin concentration in the CS group (Table 3) and the time point for blood collection (blood samples were collected before the first meal in the morning). According to a previous report, the average retention time of starch digestion in small intestine is about $4 \mathrm{~h}$, postprandial

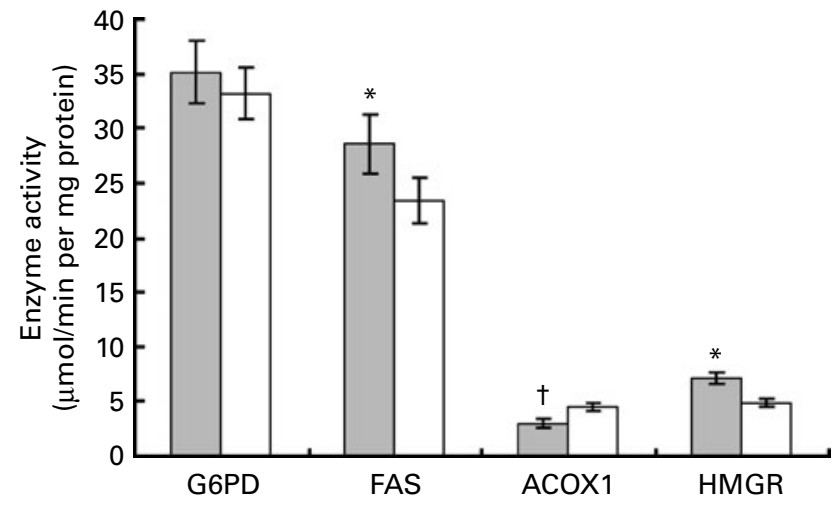

Fig. 2. Effect of different dietary starches on the activities of lipid metabolic enzymes. Mean values were significantly different: ${ }^{*} P<0.05, \dagger P<0.10$ $\square$, cassava starch (CS); $\square$, maize starch (MS). G6PD, glucose-6-phosphate dehydrogenase; FAS, fatty acid synthase; ACOX1, acyl-CoA oxidase 1; HMGR, HMG-CoA reductase.

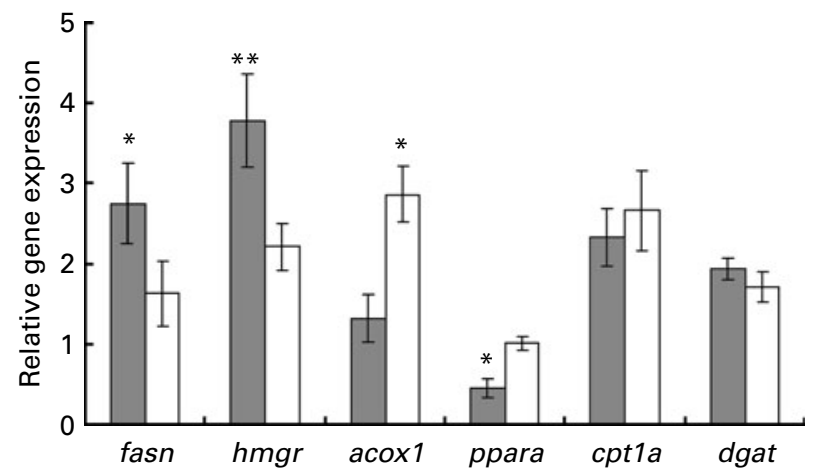

Fig. 3. Effect of different dietary starches on hepatic gene expression. The relative expression was calculated as the ratio of target gene to internal reference gene. Mean values were significantly different: ${ }^{*} P<0.05$; ${ }^{\star \star} P<0.01$. $\square$, Cassava starch; $\square$, maize starch; fasn, fatty acid synthase; hmgr, 3-hydroxy-3-methylglutaryl-coenzyme A reductase; acox1, acyl-CoA oxidase 1 ; cpt1a, carnitine palmitoyltransferase 1A; dgat, diacylglycerol acyltransferase.

circulated glucose as well as other metabolites may change periodically $^{(10)}$. The present results, however, agree well with previous findings showing that ingestion of a quickly digested carbohydrate significantly elevated the plasma TAG and insulin concentrations in rats ${ }^{(21)}$. Furthermore, a stronger insulinaemic response was previously observed both in humans ${ }^{(22)}$ and other monogastric animals ${ }^{(23-25)}$ after ingestion of starches high in amylopectin. We also measured the concentrations of serum GH and glucagon. GH is a protein-based polypeptide hormone capable of stimulating growth and cell reproduction and regeneration in humans and other animals, whereas both insulin and glucagon are important hormones involved in carbohydrate metabolism. In the present study, no significant differences were observed for serum GH and glucagon concentration between the two groups.

The liver is the central player in whole-body energy homoeostasis. We have found that ingestion of CS deposited more lipids in the liver (Table 3). Similar results were observed in a rat model, which showed that a diet high in rapidly absorbed carbohydrate causes hepatic steatosis ${ }^{(21)}$. In the present study, the liver total fat concentration exceeded $8 \%$ in the CS group, which indicated a moderate fatty liver. The elevated liver fat concentration in the CS group might result from the elevated insulin concentration since it has long been looked as one of the most important hormones to activate the transcription of lipogenic enzymes ${ }^{(4,26)}$. This hypothesis was also verified by the measurements of the enzyme activities produced in liver tissues (Fig. 2). Fatty acid synthase plays a key role in fatty acid synthesis, whereas 3-hydroxy-3-methylglutaryl-CoA reductase is the rate-controlling enzyme of the mevalonate pathway that produces cholesterol and other isoprenoids ${ }^{(27,28)}$. The present results indicated that the activities of both enzymes were elevated in the CS group $(P<0.05)$ However, ingestion of CS significantly decreased the activity of acyl-CoA oxidase - a key enzyme involved in the fatty acid $\beta$-oxidation pathway ${ }^{(29,30)}$.

To explore the mechanisms behind these metabolic responses, we analysed the transcription levels of six important genes involved in lipid metabolism. Ingestion of CS 
significantly activated the transcription of lipogenic genes fatty acid synthase and 3-hydroxy-3-methylglutaryl-coenzyme A reductase (Fig. 3). The acox1-encoded protein is the first enzyme of the fatty acid $\beta$-oxidation pathway, and defects in this gene result in accumulation of very long-chain fatty acids in the body ${ }^{(31)}$. We found that the transcription of acox1 was down-regulated in the CS group (Fig. 3). The real-time PCR results agree well with the enzyme activities produced in the liver (Fig. 2). The PPAR $\alpha$-encoded protein is an important transcriptional factor involved in the regulation of energy metabolism ${ }^{(32)}$. In the present study, the transcription of PPAR $\alpha$ was down-regulated in the CS group (Fig. 3). PPAR $\alpha$ belongs to the PPAR subfamily of nuclear receptor and facilitates energy combustion by activating the transcription of catabolic genes (i.e. FABP3, CYP4A1 and ADIPO; Fatty acid binding protein 3, cytochrome $\mathrm{P} 450$ and adiponectin, respectively) involved in lipid catabolism ${ }^{(33)}$. The role of PPAR in hepatic steatosis has been fully investigated ${ }^{(34)}$. The present results indicated that the ingestion of starches with more amylopectin may increase the incidence of hepatic steatosis by down-regulation of the PPAR $\alpha$ signalling pathway. Therefore, PPAR $\alpha$ can be a valuable target for nutritional intervention during the process of steatosis, and starches with less amylopectin may help prevent or treat obesity and fatty liver in humans.

In summary, the present results suggested that the metabolic responses of weaned pigs fed with different dietary starches may vary widely depending on their composition, and ingestion of starches that are high in amylopectin not only induces a stronger insulinaemic response, but also leads to an up-regulation of lipogenesis and steroidogenesis in the liver.

\section{Acknowledgements}

J. H. and B. Y. participated in the experimental design, carried out the molecular and biochemical experiments, participated in data interpretation and helped draft the manuscript. B. Y. conceived the study. D. C. and K. Z. directly supervised the project, participated in its experimental design and data interpretation. J. H. was also responsible for writing the manuscript. The authors state that there are no conflicts of interest in this field. This work was supported by Youth Fund Project of Sichuan Ministry of Education (grant no. 00924200) and Program for Changjiang Scholars and Innovative Research Team in University (grant no. IRTO555-5), China Ministry of Education.

\section{References}

1. Murray AJ, Lygate CA, Cole MA, et al. (2006) Insulin resistance, abnormal energy metabolism and increased ischemic damage in the chronically infracted rat heart. Cardiovasc Res 71, 149-157.

2. Ghusain-Choueiri A \& Rath EA (1995) Effect of carbohydrate source on lipid metabolism in lactating mice and on pup development. Br J Nutr 74, 821-831.
3. Reddy JK \& Hashimoto T (2001) Peroxisomal $\beta$-oxidation and peroxisome proliferator-activated receptor $\alpha$ : an adaptive metabolic system. Annu Rev Nutr 21, 193-230.

4. Uyeda K \& Repa JJ (2006) Carbohydrate response element binding protein, ChREBP, a transcription factor coupling hepatic glucose utilization and lipid synthesis. Cell Metab 4, 107-110.

5. Yudkin J (1964) Patterns and trends in carbohydrate consumption and their relation to disease. Proc Nutr Soc $\mathbf{2 3}$, $149-162$.

6. MacDonald I \& Braithwaite D (1964) The influence of dietary carbohydrates on the lipid pattern in serum and in adipose tissue. Clin Sci 27, 23-30.

7. Reiser S, Hallfrisch J, Michaelis OE, et al. (1979a) Isocaloric exchange of dietary starch and sucrose in humans: I. Effects on levels of fasting blood lipids. Am J Clin Nutr 32, 1659-1669.

8. Reiser S, Handler HB, Gardner LB, et al. (1979b) Isocaloric exchange of dietary starch and sucrose in humans: II. Effects on fasting blood insulin, glucose, and glucagon and on insulin and glucose response to a sucrose load. Am J Clin Nutr 32, 2206-2216.

9. Camp LK, Southern LL \& Bidner TD (2003) Effect of carbohydrate source on growth performance, carcass traits, and meat quality of growing-finishing pigs. J Anim Sci 81, 2488-2495.

10. Stevneb A, Sahlström S \& Svihus B (2006) Starch structure and degree of starch hydrolysis of small and large starch granules from barley varieties with varying amylose content. Anim Feed Sci Tech 130, 23-38.

11. Fugui Y, Zhenzhen Z, Ju H, et al. (2010) Digestion rate of dietary starch affects systemic circulation of amino acids in weaned pigs. Br J Nutr 103, 1404-1412.

12. Deng J, Wu X, Bing S, et al. (2009) Dietary amylose and amylopectin ratio and resistant starch content affects plasma glucose, lactic acid, hormone levels and protein synthesis in splanchnic tissues. J Anim Physiol Nutr 94, 220-226.

13. Englyst HN, Veenstra J \& Hudson GJ (1996) Measurement of rapidly available glucose (RAG) in plant food: a potential in vitro predictor of the glycaemic response. Br J Nutr $\mathbf{7 5}$, $327-337$.

14. Bird AR, Brown IL \& Topping DL (2000) Starches, resistant starches, the gut microflora and human health. Curr Issues Intest Microbiol 1, 25-37.

15. National Research Council (1998) Nutrient Requirements for Swine, 10th ed. Washington, DC: National Academy Press.

16. Folch J, Lees M \& Sloane Stanley GH (1957) A simple method for the isolation and purification of total lipides from animal tissues. J Biol Chem 226, 497-509.

17. Hercberg S, Galan P, Preziosi P, et al. (2004) The SU. VI. MAX Study: a randomized, placebo-controlled trial of the health effects of antioxidant vitamins and minerals. Arch Intern Med 164, 2335-2342.

18. Ide T, Watanabe M, Sugano M, et al. (1987) Activities of liver mitochondrial and peroxisomal fatty acid oxidation enzymes in rats fed trans-fat. Lipids 22, 6-10.

19. Pfaffl MW (2001) A new mathematical model for relative quantification in real-time RT-PCR. Nucleic Acids Res 29, e25.

20. Wolever TMS (2000) Dietary carbohydrates and insulin action in humans. Br J Nutr 83, Suppl. 1, 97-102.

21. Scribner KB, Pawlak DB \& Ludwig DS (2007) Hepatic steatosis and increased adiposity in mice consuming rapidly vs. slowly absorbed carbohydrate. Obesity 15, 2190-2199.

22. Behall KM, Scholfield DJ \& Canary J (1988) Effect if starch structure on glucose and insulin responses in adults. $\mathrm{Am} \mathrm{J}$ Clin Nutr 47, 428-432. 
23. Krezowski PA, Nuttall FQ, Gannon MC, et al. (1987) Insulin and glucose responses to various starch-containing foods in type II diabetic subjects. Diabetes Care 10, 205-212.

24. Kabir M, Rizkalla SW, Champ M, et al. (1998) Dietary amylase-amylopectin starch content affects glucose and lipid metabolism in adipocytes of normal and diabetic rats. J Nutr 128, 35-43.

25. Liu JG, Zhang P, Bin SY, et al. (2007) Effects of different dietary starch constituents on levels of blood glucose and insulin of weaned pigs (article in Chinese). Food Sci 28, 315-319.

26. Horton JD, Goldstin JL \& Brown MS (2002) SREBPs: activators of the complete program of cholesterol and fatty acid synthesis in the liver. J Clin Invest 109, 1125-1131.

27. Smith S, Witkowski A \& Joshi AK (2003) Structural and functional organization of the animal fatty acid synthase. Prog Lipid Res 42, 289-317.

28. Meigs TE, Roseman DS \& Simoni RD (1996) Regulation of 3-hydroxy-3-methylglutaryl-coenzyme A reductase degra- dation by the nonsterol mevalonate metabolite farnesol in vivo. J Biol Chem 271, 7916-7922.

29. Kawaquchi A, Tsubotani S, Seyama Y, et al. (1980) Stereochemistry of dehydrogenation catalyzed by acyl-CoA oxidase. J Biochem 88, 1481-1486.

30. Osumi T, Hashimoto T \& Ui N (1980) Purification and properties of acyl-CoA oxidase from rat liver. J Biochem $\mathbf{8 7}$, 1735-1746.

31. Kim S, Sohn I \& Ahn JL (2004) Hepatic gene expression profiles in a long-term high-fat diet-induced obesity mouse model. Gene 340, 100-109.

32. Michalik L, Auwerx J \& Berger JP (2006) International union of pharmacology. LXI. Peroxisome proliferator-activated receptors. Pharmacol Rev 58, 726-741.

33. Evans RM, Barish GD \& Wang YX (2004) PPARs and the complex journey to obesity. Nat Med 10, 1-7.

34. IP E, Farrell GC, Robertson G, et al. (2003) Central role of PPARa-depentent hepatic lipid turnover in dietary steatohepatitis in mice. Hepatology 38, 123-132. 